\title{
Modular Prosthesis versus Laminated Prosthesis- User satisfaction analysis
}

\author{
Authors \\ Priyadarshini.C.S ${ }^{1}$, Debbie Aishwarya Sathya ${ }^{2}$ \\ ${ }^{1}$ Madras Medical College, Government Institute of Rehabilitation Medicine, Chennai, India \\ Email: aishdeepthi@yahoo.com \\ ${ }^{2}$ Sree Balaji Medical College, Chennai, India
}

\begin{abstract}
Aim: To analyse the two commonly used prosthesis namely the Laminated Exoskeletal Transtibial (TT) Patellar Tendon Bearing socket Prosthesis and the Modular Transtibial Total Surface Bearing Socket (TSBS) Prosthesis for persons with Below Knee amputation in terms of appearance and utility and also to identify the demographics profile in the study group.

Method and Materials: A cross- sectional questionnaire study was designed for 30 unilateral Transtibial (Below Knee) amputees of which 15 were using Laminated TT Prosthesis and 15 were using Modular TT Prosthesis for more than lyear.The study was conducted between Jan 2016 to Dec 2016. Outcome measureUser satisfaction was analysed using Prosthesis Evaluation Questionnaire PEQ-appearance and PEQ utility scales. Statistical analysis used: Paired T test was used to analyse the results and $p$ value found between the two groups for PEQ-appearance and utility using SPSS version 21 computer software.

Results: $93.3 \%$ (14 subjects) using Modular Prosthesis were satisfied with the utility of their prosthesis compared to only 46.6\% (7 subjects) in the Laminated Prosthesis group. Paired T test was statistically significant between two prosthesis group (p value <0.05). 86.6\% (13 subjects) using Modular Prosthesis were satisfied with the appearance of their prosthesis compared to only $40 \%$ (6 subjects)) in the Laminated Prosthesis group which was statistically significant ( $p$ value $<0.05$ ).

Conclusion: Comparing Modular Transtibial Prosthesis with conventional laminated Transtibial prosthesis, modular prosthesis is by far superior in terms of utility and appearance.
\end{abstract}

Keywords: Prosthesis, transtibial, amputation, questionnaire, satisfaction.

\section{Introduction}

According to the World Health Organization (WHO) report on disability ${ }^{[1]}$ there are over a billion people including children with disabilities worldwide, corresponding to about $15 \%$ of the world population; $80 \%$ of the people with disabilities are currently living in low-income countries. ${ }^{[2]}$

There has always been the desire to replace the lost part for functional, cosmetic reasons or for a combination of both. Since long most of the limb fitting centres in India including Government Institute of Rehabilitation, Chennai were providing only Laminated Exoskeletal (TT) Patellar Tendon Bearing socket Prosthesis. The entire process of fabrication and final finishing of this prosthesis is cumbersome as well as time consuming which leads to the patient staying for a long period of time in hospital $^{[3]}$. Understanding these problems an Endoskeleton variety of Prosthesis namely Modular Prosthesis was developed. With the introduction of endoskeletal prosthesis the prosthetic design has 
dramatically improved, especially considering the weight and material selection for it. In the past, wood, aluminium, steel and leather were used. Today fabrication with plastic laminate/composite fibre over a plaster cast mould of the stump is considered standard. Prosthetic cost of treating a patient with Modular Socket System is significantly higher than treating a patient with plaster casting with standard laminated socket ${ }^{[4]}$.

There are several studies done to compare the patient satisfaction of these two types of prostheses but no such study was done in a government run institute in Tamilnadu, south India. It is on this basic idea that this present study was done in our set-up.

\section{Material and Method}

30 Transtibial amputees of which 15 using Laminated TT Prosthesis patellar tendon bearing (PTB) socket and 15 using Modular TT Prosthesis TSBS for more than 1 year attending Government run Rehabilitation Institute, Chennai were selected for the study which was conducted between Jan 2016 to Dec 2016.

Inclusion criteria were persons having a unilateral trans-tibial amputation, age between 20- 60 years, using either Laminated or Modular Transtibial Prosthesis for more than 1 year, willingness to cooperate in the study, no problems in the sound leg such as fracture and deformities and without residual limb swelling or wound. Exclusion criteria were persons without prosthesis and unmotivated persons.

All the subjects had a general health check up and were explained about the harmlessness and noninvasiveness of the study. A case history format, questionnaires as per published PEQ (Prosthesis evaluation questionnaires) and consent form was filled for each of the selected cases. Since most subjects were non-English speaking, questionnaire was interviewer-administered by prosthetists who were fluent in both English and the local language that the participants were speaking. Answers were also translated back to English.

\section{Outcome measure: Prosthesis Evaluation Questionnaire (PEQ)}

Subject's satisfaction with the prosthesis was assessed by Prosthesis Evaluation Questionnaire $(\mathrm{PEQ})^{[5]}$ which is widely used to evaluate the effects on TT amputees prosthesis-related quality of life and its reliability and validity have previously been assessed and approved. The questionnaire consists of 9 validated scales which are ambulation, appearance, frustration, perceived response, residual limb health, social burden, sounds, utility, and wellbeing. Each scale is comprised of multiple questions, with a linear analogical scale response format. The visual analog scale is scored as a continuous numerical variable measured as the distance in millimeters from the left endpoint of the line to the point at which the respondent's mark crosses the line. Each line is $100 \mathrm{~mm}$ long and measured from the left (0-100). The questions are worded and a higher number (toward the right) will correspond with a more positive response. The scales can be used independently, depending upon the need. Both composite score and individual scale scores are permitted. To calculate any of the scale scores, the average (arithmetic mean) of all the questions which make up that particular scale is computed. In our study we tested PEQ appearance and utility scales and reported here.

For Utility the following questions were asked

Over the past four weeks rate,

Q 1. the fit of your prosthesis

Q 3.the weight of your prosthesis

Q 4.your comfort while standing when using your prosthesis

Q 5. your comfort while sitting when using your prosthesis

Q 6.how often you felt off balance while using your prosthesis

Q 7.the feel (such as the temperature and texture) of the prosthesis (sock, liner, socket) on your residual limb (stump)

Q 8.the ease of putting on (donning) your prosthesis. For Appearance the following questions were asked Over the past four weeks rate,

Q 1. how your prosthesis has looked 
Q 2. the damage done to your clothing by your prosthesis

Q 3. the damage done to your prosthesis cover

Q 4. your ability to wear the shoes (different heights, styles) you prefer

Q 5. how limited your choice of clothing was because of your prosthesis

After the data was collected, it was analysed for both descriptive \& international statistics by entering the data into a computer \& statistically analysed using SPSS version 21 and $p$ value calculated with paired $\mathrm{T}$ test. $\mathrm{p}$ value $<0.05$ was considered significant.

\section{Results}

A total of 30 subjects were analysed. In our study group majority (ie) 40\% (12 subjects) were daily labourer, followed by $16.7 \%$ (05 subjects) were self employed in business, house wife $13.3 \%$ (04 subjects), student 10\% (03 subjects) unemployed $13.3 \%$ (04 subjects) and agriculturist 6.6\% (02 subjects). Train and Road Traffic Accident was the commonest cause of amputation. $70 \%$ (21 subjects) followed by peripheral vascular disease $13.3 \%$ (4 subjects) and osteomyelitis $16.6 \%$ (5 subjects)

Demographic characteristics for subjects using Laminated $(n=15)$ and Modular $(n=15)$ prosthesis is shown in Table 1

Table1. Demographic characteristics for the study group

\begin{tabular}{|l|c|c|}
\hline Variables & $\begin{array}{c}\text { Laminated } \\
\text { Prosthesis }\end{array}$ & $\begin{array}{c}\text { Modular } \\
\text { Prosthesis }\end{array}$ \\
\hline $\begin{array}{l}\text { Age in years } \\
\text { mean } \pm \text { SD }\end{array}$ & $40.07 \pm 9.72$ & $35.2 \pm 8.16$ \\
\hline Sex male/female & $11 / 4$ & $13 / 2$ \\
\hline
\end{tabular}

\section{3a. PEQ- Appearance of Prosthesis}

$86.6 \%$ (13) subjects using Modular Prosthesis were satisfied with the appearance of their prosthesis compared to only $40 \%$ (6) subjects in the Laminated Prosthesis group as shown in Table 2. Subjects with a PEQ score of more than 50 were considered to be satisfied, less than 50 were considered to be dissatisfied and with a score of 50 neutral. The differences of cosmetic acceptability between two prosthesis groups were found to be statistically significant. Paired T test for Questions 1,2,3 as well as the total score were statistically significant between two prosthesis group ( $p$ value <0.05). Question 1 was to rate the prosthesis look which was excellent for significant number of subjects. Similarly a significant number of subjects agreed that there was not much damage to their clothes by the prosthesis (question 2) or the prosthetic cover (question 3).

\section{3b. PEQ- Utility of Prosthesis}

93.3 \% (14) subjects using Modular Prosthesis were satisfied with the utility of their prosthesis compared to only $46.6 \%$ (7) subjects in the Laminated Prosthesis group as shown in Table 2. Subjects with a score of more than 50 were considered to be satisfied, less than 50 were considered to be dissatisfied and with a score of 50 neutral. Paired $\mathrm{T}$ test for all 7 Questions and total score were statistically significant between two prostheses group ( $p$ value $<0.05$ )

Table-02 PEQ- Appearance and Utility of Prosthesis $(n=30)$

\begin{tabular}{|l|c|c|c|c|}
\hline \multirow{2}{*}{$\begin{array}{l}\text { Satisfaction } \\
\text { level }\end{array}$} & \multicolumn{2}{|c|}{$\begin{array}{c}\text { Appearance of } \\
\text { Prosthesis }\end{array}$} & \multicolumn{2}{c|}{$\begin{array}{c}\text { Utility of } \\
\text { Prosthesis }\end{array}$} \\
\cline { 2 - 5 } & $\begin{array}{c}\text { Laminated } \\
(\mathrm{n}=15)\end{array}$ & $\begin{array}{c}\text { Modular } \\
(\mathrm{n}=15)\end{array}$ & $\begin{array}{c}\text { Laminated } \\
(\mathrm{n}=15)\end{array}$ & $\begin{array}{c}\text { Modular } \\
(\mathrm{n}=15)\end{array}$ \\
\hline Satisfied & 06 & 13 & 07 & 14 \\
\hline Dissatisfied & 08 & 01 & 06 & 01 \\
\hline Neutral & 01 & 01 & 02 & 00 \\
\hline
\end{tabular}

Hence from the PEQ- Appearance and PEQ- Utility questionnaire, significant differences in scores were found between laminated and modular prosthesis which is shown in graphs 1 and 2 .

\section{Graph1 PEQ- Appearance}

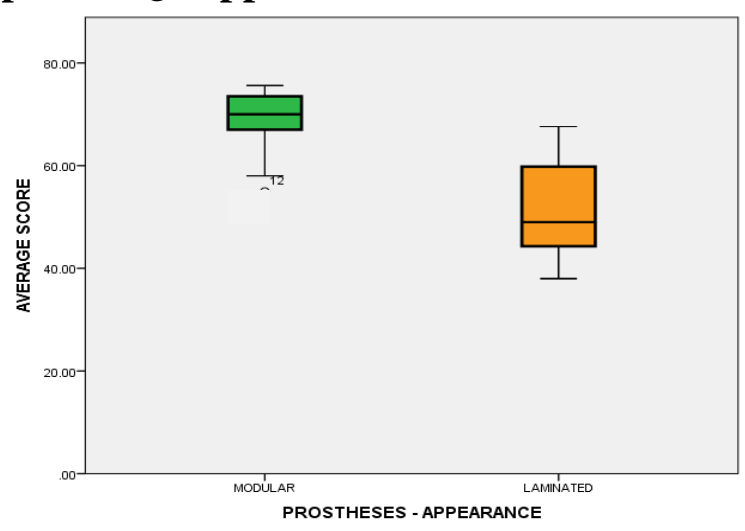




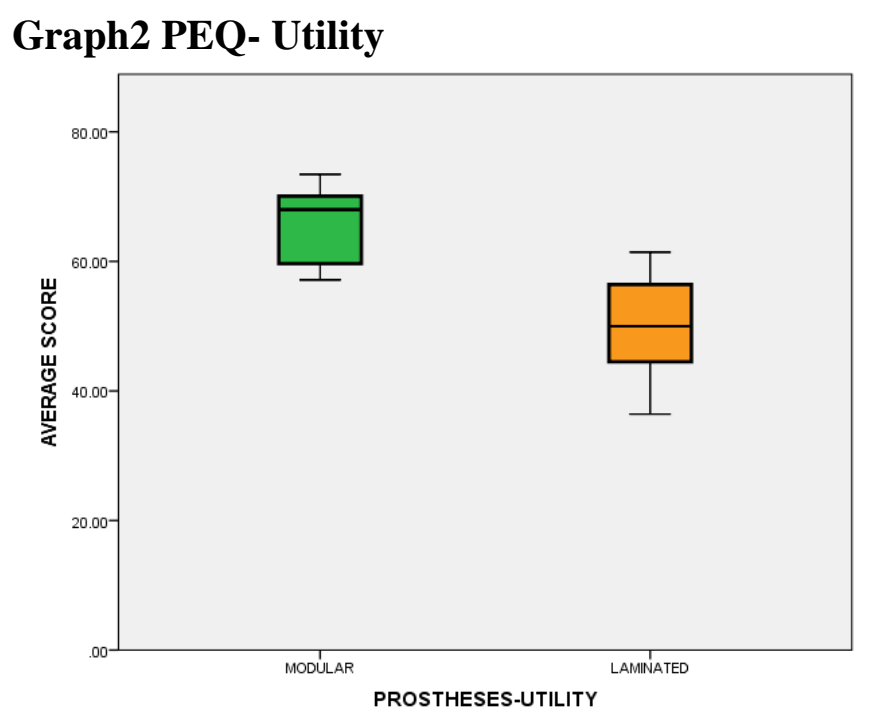

The limitations in this study: Sample size was 30 in number, due to the small size of the sample actual statistical significance could not be judged accurately. Hence the interpretation of the results should be done keeping in mind this limitation.

\section{Discussion}

The age group of 26-45 years is the active members of the society and with family and social responsibility are more exposed to accident and injury. Hence trauma due to road traffic accidents and accidents in their workplace is the most common reason for amputation in younger individuals. $^{[6]}$

In the present study where trauma is the leading cause for amputation explains the reason for the younger age group of subjects. The mean $( \pm$ SD) age of the subjects using laminated prosthesis and modular prosthesis is $40.07 \pm 9.72$ years and $37.86 \pm$ 14.43 years respectively in our study, which is comparable to several other studies ${ }^{[7,8]}$

In our study train and road traffic accident were the commonest cause of amputation 70\% (21 patients) followed by peripheral vascular disease 13.3\% (4 patients) which matches with the other studies in developing countries where the major cause of amputation was trauma. ${ }^{[9,10]}$

This study was aimed to find out patient satisfaction with respect to appearance and utility of the two types of Transtibial Prosthesis i.e. Modular TT Prosthesis and Laminated TT Prosthesis.
Selection of an ideal type of prosthesis should take into consideration patient's satisfaction with the prosthesis since it plays a key role in regaining mobility and increasing compliance ${ }^{[11,12]}$. It is documented that $40 \%$ to $60 \%$ of amputee patients are not satisfied with their prostheses. ${ }^{[13,14]}$

According to Selles RW, et al. both Laminated patellar tendon bearing sockets and Modular total surface bearing sockets performed equally well in terms of patient satisfaction, mobility-related activities performed during daily life and gait performance ${ }^{[15]}$. Compared to Laminated patellar tendon bearing sockets, Modular Total surface bearing sockets lead to greater activity levels and satisfaction in active, younger persons with traumatic cause of amputation ${ }^{[16]}$.

In our study, Laminated PTB Prosthesis was cosmetically acceptable only in $40 \%$ of subjects as compared to $86.6 \%$ subjects using Modular TSBS prosthesis. This difference is statistical significant. Due to last super finishing with cosmetic socks Modular TSBS Prosthesis is cosmetically more acceptable. In smaller institutions where there is limited financial and manpower availability relative to the patient load Modular TSBS Prosthesis is definitely going to be a better choice for Transtibial Amputees. Disadvantages of fabricating modular prosthesis are it requires expertise and prefabricated Modular kits must be available.

\section{Conclusions}

Therefore we conclude from this study that comparing Modular Transtibial TSBS Prosthesis with conventional laminated Transtibial PTB prosthesis using PEQ, modular prosthesis is by far superior in terms of utility and appearance.

\section{Acknowledgement}

The authors thank $\mathrm{Mr}$ Singaravel Mani and $\mathrm{Mr}$ Dinesh certified prosthetists for help administering questionnaire to the subjects.

\section{Source of funding: nil}

Conflict of interest: none declared 


\section{References}

1. World Health Organization (WHO). World report on disability. Geneva: WHO, 2011.

2. Eide A, Øderud T. Assistive technology in low-income countries. In: Maclachlan M, Swartz L, editors. (eds). Disability \& international development: towards inclusive global health. New York: Springer, 2009, pp. 149-160.

3. Bob Giesberts et al. The modular socket system in a rural setting in Indonesia. Prosthet Orthot Int. 2018 Jun; 42(3): 336343.

4. Normann E, Olsson A, Brodtkorb TH. Modular socket system versus traditionally laminated socket: a cost analysis.. Prosthet Orthot Int. 2011 Mar;35(1):76-80.

5. Legro MW, Reiber GD, Smith DG, del Aguila M, Larsen J, Boone. D. Prosthesis evaluation questionnaire for persons with lower limb amputations: assessing prosthesis-related quality of life. Arch Phys Med Rehabil. 1998 Aug;79(8):931-8.

6. Unnikrishnan E. P., Rakesh Rollands, Sasi M. Parambil. Epidemiology of major limb amputations: a cross sectional study from a South Indian tertiary care hospital. Int Surg J. 2017 May;4(5):1642-1646

7. Essoh JB, Bamba I, Dje Bi Dje V, Traore A, Lambin Y. Limb amputations in adults in an Ivorian Teaching Hospital. Niger J Ortho \& Trauma. 2007;6(2):61-3.

8. Chalya PL, Mabula JB, Dass RM, Ngayomela IH, Chandika AB, Mbelenge N, Gilyoma JM. Major limb amputations: A tertiary hospital experience in northwestern Tanzania. J orthopaedic surgery and research. 2012;7(1):18.

9. Paudel B, Shrestha BK, Banskota AK. Two faces of major lower limb amputations. Kathmandu University Medical J. 2005;3(11):212-6.

10. Kidmas AT, Nwadiaro CH, Igun GO. Lower limb amputation in Jos, Nigeria. East Afr Med J. 2004,81:427-9.
11. Kark L, Simmons A. Patient satisfaction following lower-limb amputation: the role of gait deviation. Prosthet Orthot Int 2011;35:225-33.

12. MohdHawari N, Jawaid M, MdTahir P, et al. Case study: survey of patient satisfaction with prosthesis quality and design among below-knee prosthetic leg socket users. Disabil Rehabil Assist Technol 2017;10:868-74.

13. Berke GM, Fergason J, Milani JR, et al. Comparison of satisfaction with current prosthetic care in veterans and service members from Vietnam and OIF/OEF conflicts with major traumatic limb loss. J Rehabil Res Dev 2010;47:361-71.

14. Dillingham TR, Pezzin LE, MacKenzie EJ, et al. Use and satisfaction with prosthetic devices among persons with trauma-related amputations: a long-term outcome study. Am J Phys Med Rehabil 2001;80:563-71.

15. Selles RW, et al. A randomized controlled trial comparing functional outcome and cost efficiency of a total surface-bearing socket versus a conventional patellar tendonbearing socket in transtibial amputees. Arch Phys Med Rehabil. 2005.

16. Safari MR, et al. Systematic review of effects of current transtibial prosthetic socket designs-Part 1: Qualitative outcomes. J Rehabil Res Dev. 2015. 